\title{
A Short Review of Cases of Extra-uterine Pregnancy admitted to the Gynæcological Department, London Hospital, 1913 to 1920.
}

\author{
By Gordon Lurer, M.D., B.C. (Cantab), F.R.C.S. (Edin.), \\ Assistant Obstetrician and Gyncecologist, London Hospital.
}

Two hundred and fifty-three cases of extra-uterine pregnancy were admitted to the Gynæcological Department of the London Hospital during the years I913-1920, under the care of Dr. Russell Andrews, Mr. Eardley Holland and Mr. Gordon Luker. The age of the youngest patient was 18 , and of the oldest $5^{2}$; the latter being a case of secondary abdominal pregnancy, with death of the foetus, some years previously.

Operation was performed in 240. In 148 of these the anatomical and clinical condition was placed in a special class, thus: Acute rupture of the tube was noted in 68 cases; tubal mole was found in 51 cases; tubal abortion occurred in 29 cases.

Of the 240 operations performed, 37 , or 15 per cent., were special emergency operations in which the condition of the patient demanded immediate interference. The series includes six deaths--three from shock and hæmorrhage, one from pulmonary embolus, one from broncho-pneumonia, one from peritonitis. Of the first, one death occurred in a patient who was not operated upon, but collapsed and died suddenly some hours after admission to Hospital with a tentative diagnosis in the receiving room of "retroverted gravid uterus."' Post-mortcm, a large pelvic hæmatocele was found. Two other deaths from shock and collapse occurred within twelve hours of operation, and raised the question whether it is not advisable to delay operation in some cases in which shock is profound.

Rare conditions.--These include one case of old-standing ectopic gestation and three cases of pregnancy in a rudimentary horn.

In a more detailed examination of 42 cases which were admitted in the year 1920, the following points have been noted: In 30 per cent. no previous pregnancy had occurred. In those in whom previous pregnancy had occurred the number of children was variable, though rarely more than four. In one patient, however, ro children 
were noted. Some considerable period of sterility had generally elapsed since the last confinement. Abortion does not seem to hold any prominent place in the ætiology of the condition. There were two cases of repeated tubal pregnancy. Inflammation in the pelvis or other tube was definitely noted in I I cases.

Symptoms.-In 28 cases, i.e., 66 per cent., the ordinary history of amenorrhœa was obtained. In Io cases a period had not been missed; that is to say, bleeding occurred at or within a month from the last menstrual period. In four cases there was no bleeding at all up to the time of operation. This, in our opinion, is rare, and indicates an atypical condition; in one of these cases, for instance, the abdomen was full of blood which had come from a ruptured Graafian follicle. No evidence of pregnancy in the tube or ovary cquld be found. Apart from this, it seems probable that, when no pleeding from the uterus occurs, the ovum is still living.

Pain.-In nearly half the cases acute pain occurred as the first symptom. In another 16 per cent., pain was the first symptom but was not really acute. In several cases a dull " girdle" pain was complained of, and was found to be of some value in assisting diagnosis in a doubtful case.

Bleeding.-There was some bleeding from the uterus in all but four cases. In about half the cases bleeding did not occur unti1 after the first attack of pain. In more than one-third of the cases, however, bleeding was the first symptom. Thus it seems fair to conclude that typical symptoms of acute pain, followed by a small amount of bleeding, are by no means constant.

Decidual Cast of the Uterus.-This remains the pathognomonic sign of extra-uterine pregnancy, and when care is taken to keep everything that is passed per vaginam from the onset of the symptoms, a decidual cast can be found in whole or part in nearly half the cases; it is shed more often after than before operation.

The differential diagnosis from salpingitis, a small ovarian cyst and appendicitis is often difficult. The pulse-rate is the most useful guide, and if charted hourly will prevent any delay in operation which may be injurious to the patient. Any considerable rise of temperature points to an inflammatory condition rather than to extra-uterine pregnancy. In salpingitis the presence of a vaginal discharge, and in appendicitis any symptoms pointing to an intestinal affection, are the most salient points in differential diagnosis. 
Extra-Uterine Pregnancy.

(Gynæcological Department, the London Hospital.)

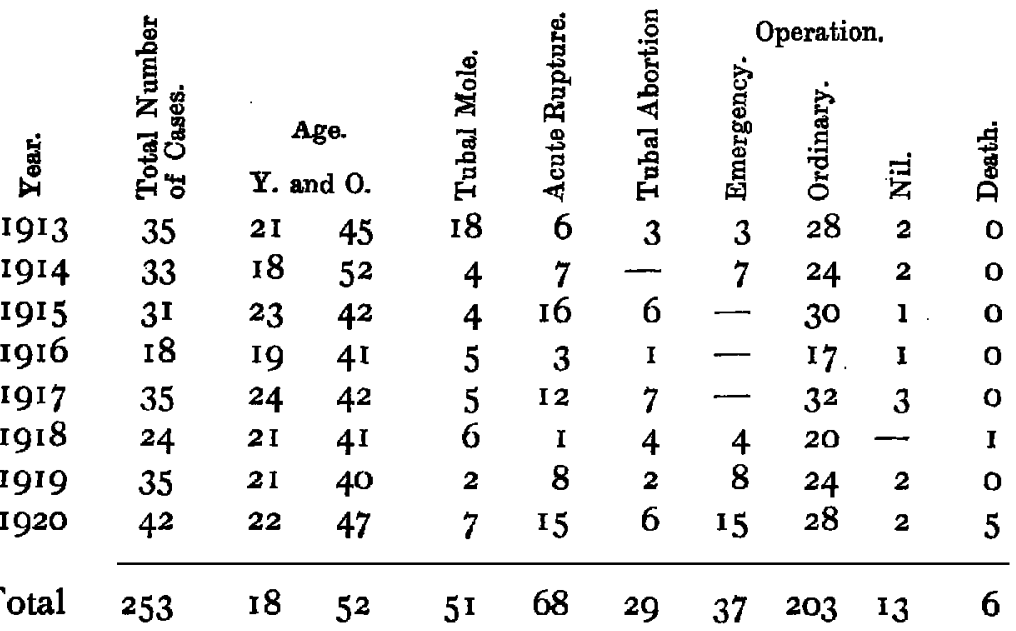

Rare Conditions :-

I Full-time Ectopic Gestation.

2 Left Rudimentary Horn.

I Right Rudimentary Horn.

Deaths -6, include :-

2 Shock and Collapse from Hæmorrhage (after operation).

I Shock and Collapse from Hæmorrhage (no operation).

I Pulmonary Embolus.

I Broncho-pneumonia.

I Peritonitis. 